recommendations; (iii) at the dissemination stage, we carry out the analyses, report results on the website and to study authors and journal editors, as well as deposit prespecified files at a public repository (OSF).

Results We completed a census to characterize the types of studies published in 2018 by the nine-journal cohort in exercise sciences. From a total of 3,205 individual references, we respectively classified 277 (9\%; min-max range, 5 to 92) and 248 (8\%; min-max range, 6 to 72) articles as RCTs and SRMAs. Currently, our three-stage process is ongoing and, from the two first months of surveillance, 38 RCTs and 27 SRMAs were eligible for analysis. We consolidated a comprehensive assessment using items from CONSORT 2010 and TIDieR checklist to appraise RCTs and from PRISMA, AMSTAR-2, and ROBIS to appraise SRMAs. In addition to full study reports with our assessment for all items, we proposed aggregated results using seven components (aggregating from 4 to 11 assessed items) that relate to: transparency, completeness, methodological rigor, participants, interventions/ exposures, outcome, and critical appraisal.

Conclusions Inspired by the Mertonian principles and Doug Altman's wisdom, the SEES Initiative is a living, scalable, open project to promote adequate reporting, feedback stakeholders toward increased research uptake, and disrupt/denounce inadequate practices whenever necessary.

\section{SURVEY OF PERCEPTION, ATTITUDES AND PRACTICES OF ANTIMICROBIAL STEWARDSHIP AMONG HEALTH WORKERS IN A NIGERIAN UNIVERSITY TEACHING HOSPITAL}

Raymond Okechukwu, Jacinta Eli-llo, Chukwudubem Onyejiaka, Joy Ebenebe, Michel Egbuniwe, Catherine Obasikene, Nri-Ezedi Chisom, Joseph Ugboaja. Nnamdi Azikiwe University Teaching Hospital, Nnewi, Nigeria

\subsection{6/bmjebm-2019-EBMLive.61}

Objectives Globally there is heightened interest in implementing hospital-wide antimicrobial stewardship program in order to contain the challenges of antimicrobial resistance. The practice of antimicrobial stewardship program in the Nnamdi Azikiwe University Teaching Hospital, Nnewi Nigeria has not been adequately researched. The objectives of this study were:

1. To assess the perception, attitudes and practices of antimicrobial stewardship program among health care workers in the Nnamdi Azikiwe University Teaching Hospital, Nnewi, Nigeria.

2. To determine the factors that influences the attitude and practices of antimicrobial stewardship program among the research participants in the study centre.

Method The study setting for this research work was the Nnamdi Azikiwe University Teaching Hospital, Nnewi, Nigeria; one of the tertiary healthcare institutions for specialized healthcare and training of healthcare professionals in Nigeria. The design for this study was a cross sectional survey among healthcare workers in the teaching hospital using structured self-administered questionnaire. Data collected were analysed using STATA software student trial version 13 after ethical approval from the institutional ethical review board. Demographic characteristics of the respondents were computed and tests for statistical significance were done using regression analysis and chi-square tests at 95\% confidence interval ( $\mathrm{p}$ value $=0.05$ )

Results Of the 190 questionnaires distributed 162 were returned, (85.3\% response). Among the respondents were 44 (27.2\%) males and 118 (72.8\%) females; with age range 21 63 years: mean age; 35.2 ( \pm 8.2) years; and median age of 34 years. The median length of service of the respondents in the teaching hospital was 5 years. There is low level of awareness of antimicrobial stewardship among the respondents. Only $6(3.75 \%)$ of the respondents considered their knowledge and skills of antimicrobial stewardship program as excellent while $54(33.5 \%)$ of them did not think that antimicrobial resistance is a serious healthcare problem. Bivariate logistic regression analysis for the predictors of antimicrobial stewardship practices were not statistically significant for respondents' knowledge of antimicrobial stewardship program matched against their age categories (p, 0.14; OR: 1.89); gender (p, 0.76; OR: 1.12); and length of service within the hospital (p, 0.17; OR: 1.64), at 95\% confidence interval.

Conclusions The respondents in this study showed overall poor knowledge and poo attitude towards the practice of antimicrobial stewardship program. There is need to create awareness through regular training and retraining of healthcare personnel and the development of functional antimicrobial stewardship program within our teaching hospitals to fit global trends and best practices. Further intervention study is required towards behavior change to improve antimicrobial stewardship practices among the healthcare personnel in the teaching hospital.

\section{THE STORY BEHIND DRUG TRADE NAMES; A DEEPER INSIGHT INTO THE PHARMACEUTICAL MARKET} 1,2,3 Yasmin Elsobky. ${ }^{1}$ El-Galaa Military Medical Complex, Cairo, Egypt; ${ }^{2}$ High Institute for
Public Heath, Alexandria, Egypt; ${ }^{3}$ NAPHS Consultancy, Alexandria, Egypt

\subsection{6/bmjebm-2019-EBMLive.62}

Objectives Drug nomenclature is an international system that helps in identifying the drugs. Trade names often reflect a characteristic of the drug or a relationship that will be of useful value for the users. The aim of this study is to find a relation between drug trade names and the reasons of their naming. Moreover, it aims to predict patters that classify drug naming patterns.

Method Cross sectional study on the drugs available in the Egyptian market from May 2017 until October 2018.

The sources of drug trade names obtained from Atlas-2 book, Avi-cenna software and Dawaa mobile application which contain all the drugs that are found in the Egyptian market. A Google search was also conducted to find out the word origin, history or stories behind some of the trade names as well as visiting the pharmaceutical companies' websites.

Results According to the analysis of the trade names, the following patterns ware observed: Drugs named according to chemical structure as Tylenol $^{\oplus}$ (n-aceTYL-para-amino-phENOL); stereochemistry Dextrose DEXTRorotatory sugar (-OSE), Levocar (LEVOdopa, CARbidopa); company's name Ciprobay denotes CIPROfloxacin and BAYar company name); drug action No-Uric ${ }^{\oplus}, \operatorname{Losec}^{\oplus}\left(\mathrm{LOW}\right.$ SECreation) Eliquis ${ }^{\circledast}$ (excellent liquidity); the disease state Allergex ${ }^{\circledast}$, Allergyl $^{\oplus}$ improve ALLERGY symptoms; pharmacological class Anti Cox II ; special population Centrum KIDS ${ }^{\circledast}$, Otrivin BABY ${ }^{\circledR}$, Vitamount-for- 